\title{
Dermatological Findings Observed After Renal Transplantation in Patients
}

\author{
(1) Melek Aslan Kayıran ${ }^{1}$, (1) Hasan Aksoy ${ }^{1}$, (1) Sabahat Alıșır Ecder², (1) Necmettin Akdeniz \\ 1Istanbul Medeniyet University, Goztepe Prof. Dr. Suleyman Yalcin City Hospital, Clinic of Dermatology, Istanbul, Turkey \\ ${ }^{2}$ Istanbul Medeniyet University, Goztepe Prof. Dr. Suleyman Yalcin City Hospital, Clinic of Internal Medicine, Division of Nephrology, Istanbul, Turkey \\ ${ }^{3}$ Memorial Sisli Hospital, Clinic of Dermatology, Istanbul, Turkey
}

\section{ABSTRACT}

Background: Renal transplant recipients tend to have a variety of skin diseases due to multiple immunosuppressive medications, accompanying co-morbidities and prolonged survival with the transplantation procedure. The aim of this cross-sectional study is to present dermatological findings and the contributing factors in renal transplant recipients.

Materials and Methods: Forty-one renal transplant recipients were examined by dermatologists between February and May 2021. The etiology of the chronic renal failure, the age at the time of the transplantation, time after transplantation, current medications, donor features, socio-demographic features of the patients, history of dialysis and accompanying co-morbidities were questioned.

Results: Average age of patients (27 male, 14 female) was $49.9 \pm 11.2$ years. Average time after renal transplantation was $12.8 \pm 6.6$ years. $87.8 \%$ of the patients were taking mycophenolate mofetil; $78 \%$ systemic steroids, $68.3 \%$ tacrolimus, $22 \%$ cyclosporin-A and $12.2 \%$ azathioprine. Skin signs due to immunosuppressive medications were more frequent in younger patients $(p=0.031)$. Xerosis of the skin due to immunosuppressive medications was found in $41.5 \%$ and acneiform eruption in $34.1 \%$ of the patients. For skin infections, superficial fungal infections were the most frequent (73.2\%), 56.1\% of them being onychomycosis. Warts (22\%) were the most frequent viral skin disease (31.7\%). Viral and fungal skin infections were significantly more common in patients who are taking tacrolimus ( $p=0.024$ and $p=0.002$, respectively). Fungal skin infections were more common in patients with prolonged and high-dose mycophenolate mofetil treatment ( $p=0.021$ and $p=0.005$, respectively). Kaposi sarcoma was found in one of the patients and in situ squamous cell carcinoma was found in another patient. The most common oral lesion was gingival hyperplasia (29.3\%).

Conclusion: Fungal and viral skin infections, skin cancers, acneiform eruptions, xerosis of the skin and gingival hyperplasia are commonly seen in renal transplant recipients. Therefore, proper dermatologic follow-up examinations are crucial.

Keywords: Renal transplantation, Xerosis, Acneiform eruption, Superficial fungal infections, Warts

\section{Introduction}

Renal transplantation is the most ideal and efficient treatment option of end stage renal failure and severe chronic renal diseases, besides improving the quality of patients' lives [1]. However, immunosuppressive treatment which is usually necessary for lifetime to prevent the rejection of the transplanted kidney makes the patients prone to skin diseases like infections and nonmelanoma skin cancers $[2,3,4]$. In addition, several accompanying comorbidities and prolonged life expectancy after transplantation increase this trend [5]. For these reasons, it is very important for the renal transplant recipients to undergo patients who have had 
kidney transplantation have regular follow-up for with dermatologic examinations. This is necessary not only to prevent the impact of possible dermatological diseases on the patients' quality of life but also to properly manage the complications that may occur.

The aim of this cross-sectional study is to review the skin diseases in renal transplant recipients and possible contributing factors that may affect them such as immunosuppressive medications, time after transplantation and donor characteristics.

\section{Materials and Methods}

We conducted our research according to the World Medical Association Declaration of Helsinki and obtained the approval of the Istanbul University Medeniyet Training and Research Hospital Local Ethics Committee (date: 13.01.2021, approval number: 0003). Forty-one patients who were being followedup after kidney transplantation at the Nephrology Department of the Medeniyet Training and Research Hospital of the Istanbul University, and agreed to participate in the study were examined by dermatologists of the same hospital between February $1^{\text {st }}$ and May $30^{\text {th }}, 2021$. Patients were questioned about their socio-demographic characteristics, age at the time of renal transplantation, disease that caused renal failure, donor characteristics, the type and duration of the immunosuppressive treatment, accompanying comorbidities and the history of dialysis. The patients provided written consent stating that they agreed to participate in the study.

\section{Statistical Analysis}

The data obtained in the study were analysed with the Statistical Package for the Social Sciences IBM 25.0 package data program. Descriptive statistics (mean-standard deviation) and frequency distributions are presented. Independent group comparisons test statistics on continuous measurements were calculated by MannWhitney $U$ test and binary group comparisons were calculated by chi-square test. The confidence level is set at 95\%. A p value below 0.05 was considered significant.

\section{Results}

Socio-demographic Characteristics, Transplantation History and Accompanying Diseases of the Patients

A total of 41 patients participated in our study, 14 of whom were women and 27 of whom were men. The mean age of the patients was $49.9 \pm 11.2$ years (21-70). The socio-demographic characteristics of the patients, the diseases that necessitated the transplantation, the time after transplantation, the characteristics of the donor and accompanying comorbidities are summarized in Table 1.

Of all the patients, $90.2 \%$ were treated with either peritoneal dialysis or haemodialysis before transplantation. Average duration of dialysis was $1.9 \pm 0.3$ years. Two of the patients $(4.9 \%)$ had admitted to the dermatology outpatient clinic while on dialysis. A patient was diagnosed with dermatofibroma, and the other one was treated for tinea pedis and corporis. Eight patients (19.5\%) admitted to the dermatology department by themselves due to skin problems after transplantation. These patients were diagnosed with seborrheic keratosis, stasis dermatitis, zona zoster, irritant contact dermatitis, dermal nevus, macular drug eruption due to antidiabetic medications, genital warts and pityriasis versicolor. Thirty-four (82.9\%) of the patients had accompanying comorbidities, hypertension being the most frequent one (53.6\%), followed by diabetes mellitus (26.8\%) and hypercholesterolemia (7.3\%). Five patients (12.2\%) had systemic cancers. Two had prostate cancer, 2 had papillary thyroid cancer and one had colon carcinoma.

\section{The Immunosuppressive Treatment and Skin Signs Associated with These Medications}

The medications, doses and duration of the treatment of patients after renal transplantation are summarized in Table 2. For systemic treatment, $87.8 \%$ of patients were taking mycophenolate mofetil, $78 \%$ corticosteroids, $68.3 \%$ tacrolimus, $22 \%$ cyclosporin-A and $12.2 \%$ azathioprine.

Skin findings due to immunosuppressive drugs were observed in $85.4 \%$ of patients. These findings were more frequent in young patients. The mean age of those with skin findings was 48 years \pm 11 years, while those without skin findings were 59 years \pm 8 years $(p=0.031)$.

Most commonly, $41.5 \%$ of patients had xerotic body skin followed by acneiform eruption in $34.1 \%$, seborrhoea on the face in $31.7 \%$, sebaceous gland hyperplasia in $24.4 \%$, gingival hyperplasia in $22 \%$, flushing in $17.1 \%$, facial telangiectasia in $12.2 \%$, demodicosis in $12.2 \%$, striae in $9.8 \%$, moon face in $7.3 \%$, purpura in $7.3 \%$, dorsocervical fat accumulation in $2.4 \%$ of the patients (Figure 1 ).

\section{Skin Infections}

Superficial fungal infections were found in $73.2 \%$, viral infections in $31.7 \%$, parasitic (all cases demodicosis) in $12.1 \%$ and bacterial skin infections in $9.8 \%$ of the patients.

Fungal infections were more common as the time after transplantation was prolonged. The mean time after transplantation was $14 \pm 7$ years in patients with fungal infections, while it was $9 \pm 4$ years who did not have fungal infections $(p=0.036)$. In addition, fungal infections were common in patients who were taking tacrolimus and mycophenolate mofetil for a longer period. Average duration of tacrolimus therapy was $98 \pm 99$ months in patients with fungal infections, while it was $86 \pm 51$ months in patients without fungal infection $(p=0.002)$. For mycophenolate mofetil, average duration of therapy was $173 \pm 85$ months in patients with fungal infections vs $72 \pm 77$ months $(p=0.021)$. Fungal infections 
were also more frequent in patients who were on higher doses of mycophenolate mofetil (1135 $\pm 487 \mathrm{mg} /$ day vs $456 \pm 401 \mathrm{mg} /$ day, $p=0.005)$. For the distribution of fungal infections, onychomycosis of the feet was found in $48.8 \%$ of patients, onychomycosis of hands in $7.3 \%$ of, tinea pedis in $43.9 \%$, pityriasis versicolor in $24.4 \%$, tinea cruris in $2.4 \%$ and candida infections in $2.4 \%$ (Figure 2A, 2B). One of the patients had a history of deep fungal infection in the leg which had healed with scar formation.

Viral skin infections were more common in patients with longer duration of accompanying comorbidities ( $18 \pm 10$ years vs $4 \pm 7$ years, $p=0.002)$. Of all patients on tacrolimus treatment, $57.1 \%$ had viral skin infections, while $42.9 \%$ did not $(p=0.024)$. However, neither duration nor dose of tacrolimus were correlated with viral infections $(p=0.822 ; p=0.219$, respectively). Warts were the most common viral skin infection (22\%) (Figure 2C). The most common location were feet (12.2\%), followed by hands (9.8\%), and other parts such as body and face (7.3\%). Zona zoster was found on the leg of a patient. $12.2 \%$ of the patients had history of zona zoster with one of them recalcitrant postherpetic neuralgia. Active herpes simplex infection was found in $14.6 \%$ of patients (lips $9.8 \%$, nose $4.9 \%$ and face $4.9 \%$,

Table 1. The socio-demographic characteristics, primary diseases, and information about renal transplantation of patients

\begin{tabular}{|c|c|c|c|}
\hline & & Number & $\%$ \\
\hline \multirow{2}{*}{ Gender } & Female & 14 & 34.1 \\
\hline & Male & 27 & 65.9 \\
\hline Marital status & Single & 16 & 39.0 \\
\hline Age & & \multicolumn{2}{|c|}{$49.9 \pm 11.2$ years } \\
\hline Education level & High school and higher & 23 & 56.1 \\
\hline \multirow{3}{*}{ Smoking status } & Smoker & 8 & 19.5 \\
\hline & Non-smoker & 21 & 51.2 \\
\hline & Ex-smoker & 12 & 29.3 \\
\hline Smoking pack year & & \multicolumn{2}{|c|}{$9.2 \pm 11.5$ years } \\
\hline \multirow{4}{*}{ Are parents related } & No & 33 & 80.5 \\
\hline & Yes & 8 & 19.5 \\
\hline & Parents are sibling children & 2 & 4.9 \\
\hline & Parents are cousin children & 6 & 14.7 \\
\hline Duration after transplantation & & \multicolumn{2}{|c|}{$12.8 \pm 6.6$ years } \\
\hline Transplantation age & & \multicolumn{2}{|c|}{$38.4 \pm 10.9$ years } \\
\hline \multirow{4}{*}{ Etiology of primer renal failure } & Immunoglobulin A nephropathy & 2 & 4.9 \\
\hline & Hypertension & 7 & 17.1 \\
\hline & Vesicoureteral reflux & 2 & 4.9 \\
\hline & Unknown & 1 & 2.3 \\
\hline \multirow{4}{*}{ Donor characteristics } & Stranger & 23 & 56.1 \\
\hline & Consanguineous & 18 & 43.9 \\
\hline & Brain death & 17 & 41.5 \\
\hline & Live donor & 24 & 58.5 \\
\hline
\end{tabular}


respectively). Of the patients, $43.9 \%$ had a history of recurrent herpes simplex infection (Table 3). Molluscum contagiosum was found on the arms of a patient (Figure 2D).

Folliculitis (7.3\%) was the most commonly bacterial skin disease and paronychia of both toes was found in a patient.

\section{Malignant and Premalignant Lesions}

Malignant and premalignant lesions were found in 26\% of patients. Actinic keratosis and lentigo were seen in two patients and dysplastic nevus were seen in a patient. A patient was diagnosed with Kaposi's sarcoma which was located on the hand, foot and abdomen. In situ squamous cell carcinoma was found in one patient which was located on the back (Figure 3A). Two of the patients had a history of squamous cell carcinoma on the forehead and scalp which had been diagnosed previously.

Nevi

Various types of nevi were found in $17.1 \%$ of patients. Four patients had dermal and compound nevi, two patients had congenital nevi and a patient had nevus sebaceous (Figure 3B). Nevi were common in elderly patients; average of patients with nevi was $59 \pm 13$ years versus $48 \pm 10$ years in patients who did not have nevi $(p=0.011)$.

\section{Oral Lesions}

Various oral lesions were detected in $53.7 \%$ of the patients. Oral lesions were more common in patients who were taking tacrolimus

Table 2. Drugs usage due to kidney transplantation

\begin{tabular}{|c|c|c|}
\hline Drugs & & Number (\%) \\
\hline \multirow{4}{*}{ Systemic corticosteroid } & None & $9(22)$ \\
\hline & Yes & $32(78)$ \\
\hline & Duration (months) & $128.5 \pm 98.8$ \\
\hline & Dose (mg/day) & $3.9 \pm 2.6$ \\
\hline \multirow{4}{*}{ Tacrolimus } & None & $13(31.75)$ \\
\hline & Yes & $28(68.25)$ \\
\hline & Duration (months) & $95.1 \pm 87.9$ \\
\hline & Dose (mg/day) & $1.9 \pm 1.6$ \\
\hline \multirow{4}{*}{ Mycophenolate mofetil } & None & $5(12.25)$ \\
\hline & Yes & $36(87.75)$ \\
\hline & Duration (months) & $145.8 \pm 93.8$ \\
\hline & Dose (mg/day) & $948.5 \pm 553.1$ \\
\hline \multirow{4}{*}{ Azathioprine } & None & $36(87.8)$ \\
\hline & Yes & $5(12.2)$ \\
\hline & Duration (months) & $12.3 \pm 38.1$ \\
\hline & Dose (mg/day) & $8.54 \pm 24.1$ \\
\hline \multirow{4}{*}{ Cyclosporin-A } & None & $32(78)$ \\
\hline & Yes & $9(22)$ \\
\hline & Duration (months) & $47.7 \pm 96.8$ \\
\hline & Dose (mg/day) & $28.1 \pm 57.9$ \\
\hline
\end{tabular}

than those who did not (57.14\% and $42.86 \%$, respectively, $p=0.042$ ). Gingival hyperplasia was the most common lesion (29.3\%), followed
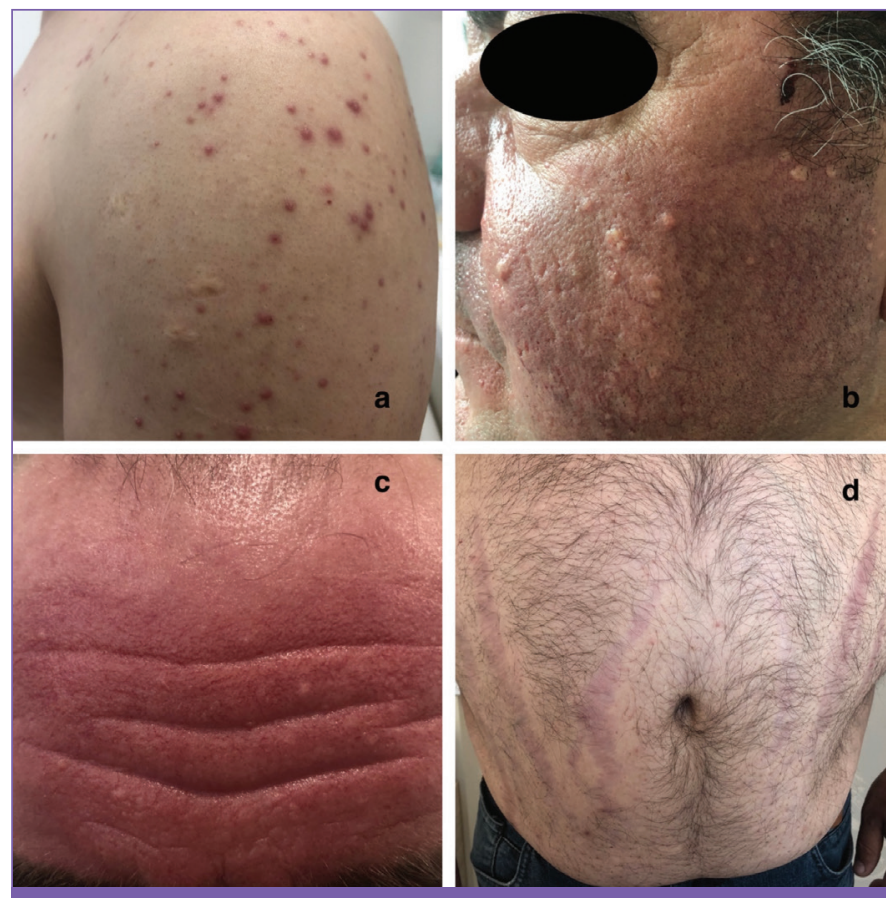

Figure 1. Skin findings of the patients due to immunosuppressive treatments. A) Acneiform eruptions on body. B) Seborrhoea, sebaceous gland hyperplasia, facial telangiectasia on the face. C) Flushing and facial telangiectasia on the face. D) Striae on the abdominal area
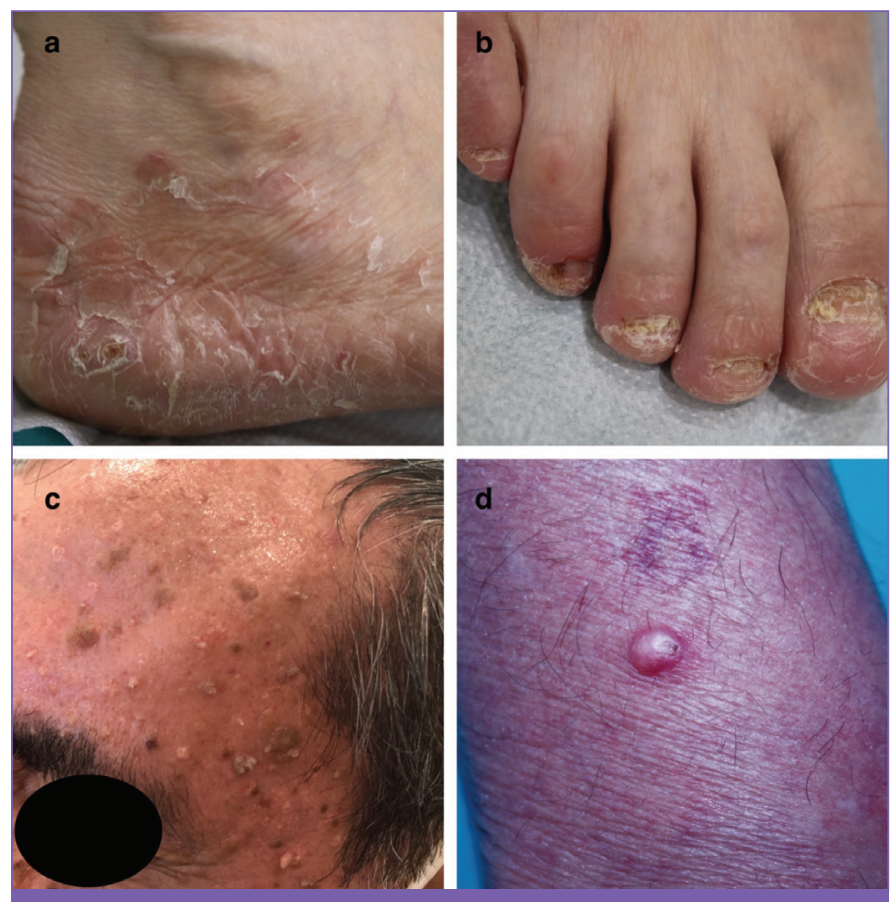

Figure 2. Skin infections of the patients. A) Tinea pedis. B) Onychomycosis on feet nails. C) Warts and also seborrheic keratosis on the face. D) Molluscum contagiosum on the arm 
by atrophic glossitis (19.5\%), hairy tongue (14.6\%) and actinic cheilitis (4.9\%) (Figure 3C).

\section{Other Skin Lesions}

Other skin lesions found in patients are summarized in Table 4. These lesions were more frequent in patients who were older at the time of transplantation (39 \pm 11 years) than the younger ones $(32 \pm 4$ years) $(p=0.038)$. They were also more frequent in elderly patients (60 \pm 9 years) than younger patients $(48 \pm 11$ years) $(p=0.026)$. In addition, ephelides, contact dermatitis, vitiligo, nail discoloration, dermatofibroma, pincer nail, half and half nail, rosacea, milium cyst, splinter haemorrhage, lipoma, ganglion cyst and hypertrophy of the shunt area were detected in different patients (Figure 3D).

\section{Discussion}

Our study has shown that patients with renal transplantation may have skin lesions and diseases of a varying spectrum, due to both the effects of the immunosuppressive medications and accompanying comorbidities. Dermatological side effects of the medications were more frequent in younger patients among which xerotic skin and acneiform eruptions were the most common ones.

Table 3. History of recurrent herpes simplex infection

\begin{tabular}{|l|l|l|}
\hline \multirow{2}{|c|}{ History of herpes simplex } & None & Number (\%) \\
\cline { 2 - 3 } & Yes & $18(56.1)$ \\
\hline \multirow{2}{*}{ Which part of the body } & Lips & $17(41.5)$ \\
\cline { 2 - 3 } & Nose & $1(2.4)$ \\
\hline Number of repetitions in a year & & $3.1 \pm 2.6$ \\
\hline Recovery time & Days & $7.25 \pm 5.01$ \\
\hline $\begin{array}{l}\text { Duration of herpes simplex } \\
\text { repetition }\end{array}$ & Years & $16.9 \pm 7.1$ \\
\hline
\end{tabular}

Table 4. Other skin findings detected in patients

\begin{tabular}{|l|l|}
\hline Findings & Number (\%) \\
\hline Seborrheic keratosis & $11(26.8)$ \\
\hline Hyperpigmentation & $10(24.2)$ \\
\hline Acrochordon & $9(22)$ \\
\hline Ecchymosis & $4(9.8)$ \\
\hline Androgenic alopecia & $5(12.2)$ \\
\hline Pruritus & $4(9.8)$ \\
\hline Onychodystrophy & $4(9.8)$ \\
\hline Senile angioma & $4(9.8)$ \\
\hline Seborrheic dermatitis & $3(7.3)$ \\
\hline Telogen effluvium & $3(7.3)$ \\
\hline Onycholysis & $2(4.9)$ \\
\hline Unguis incarnatus & $2(4.9)$ \\
\hline Dermoid cyst & $2(4.9)$ \\
\hline
\end{tabular}

The most common infections were superficial fungal infections, followed by viral infections. While tacrolimus and mycophenolate mofetil increased the tendency to fungal infections, tacrolimus increased the tendency to viral infections, too. Tendency to fungal infections increases as the period after transplantation gets longer and tendency to viral infections increases with the duration of accompanying comorbidities. Renal transplant recipients are also prone to skin malignancies.

It is known that skin lesions are more common in renal transplant recipients compared to normal population [2,6,7]. Among these, skin infections especially fungal and viral infections, non-melanoma skin cancers, gingival hyperplasia, alopecia and hirsutism are reported to be most common ones $[7,8]$.

Fungal skin infections are the most common skin infections in renal transplant recipients with reported rates of $18-68 \%[2,9,10,11]$. Fungal infections were also the most common infection in our study with a slightly higher rate (73.2\%). Tendency to fungal infections increased as the time after transplantation get prolonged. Most common fungal infection was onychomycosis (56.1\%) in our study. Onychomycosis was reported at a similar rate by Sandoval et al. [12] (58\%), while Kartal et al. [13] reported only 5.3\%. Ghaninejad et al. [11] reported pityriasis versicolor in 35\% of the patients as the most common fungal infection. Pityriasis versicolor was slightly less frequent in our study (24.4\%). However, in the study by Kartal
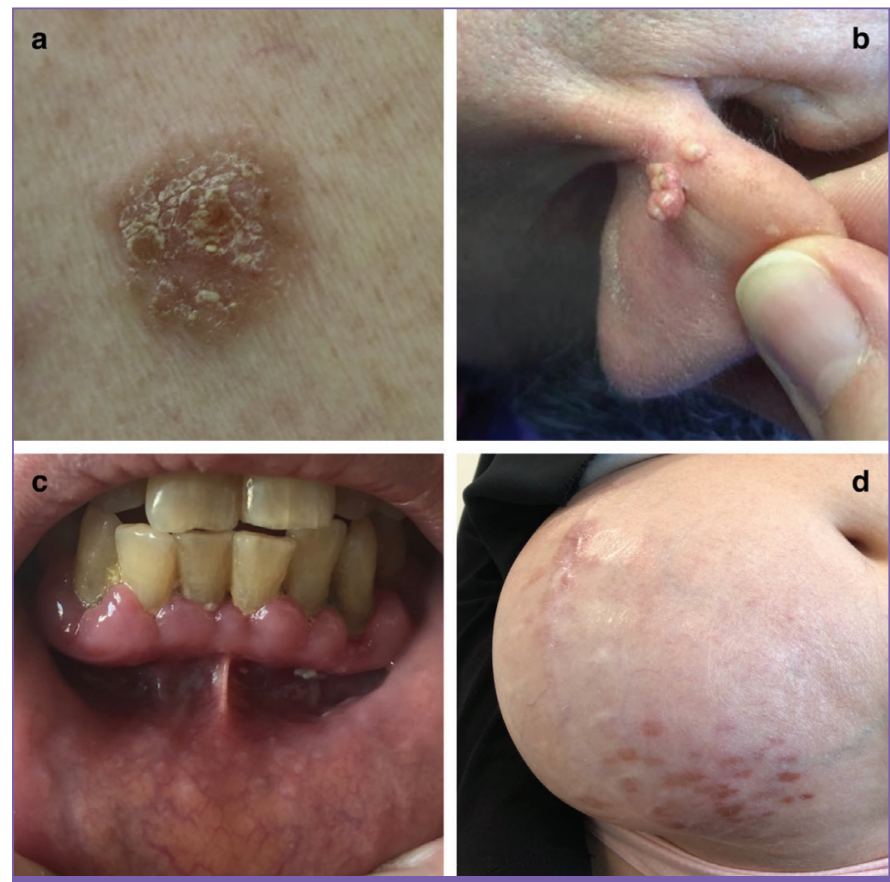

Figure 3. Different skin findings of the patients. A) In situ squamous cell carcinoma on the back of a patient. B) Nevus sebaceous on ear. C) Gingival hyperplasia. D) Hypertrophy of the shunt area on kidney seen on skin 
et al. [13], this rate was $2.1 \%$. Since superficial fungal infections are very common in society, it should be considered natural to see them frequently in renal transplantation patients undergoing immunosuppressive treatment as well.

Viral skin infections rates between $13-29.3 \%$ were reported among renal transplant recipients $[2,10]$. Warts were the most common viral infection in all studies. While the incidence of warts was reported between $15-32.3 \%$ in cross-sectional and retrospective studies, this rate increases to $92 \%$ in the follow-up cohort $[5,7,13,14,15]$. Although viral infection rates were slightly more frequent in our study (31.7\%), warts (22\%) were the most common one which is similar to the previous reports. Ghaninejad et al. [11] reported herpes infection in 34\% of their cohort. Dymock [16] reported herpes simplex infection in $39 \%$ of patients in a retrospective analysis. Moloney et al. [7] reported recurrent herpes infection in $4.6 \%$ of the patients. Active herpes infection was found in $4.6 \%$ of patients in our study, however, $43.9 \%$ of patients had a history of recurrent herpes infection. The relatively less rate of active herpes infection in our study may be attributed to the cross-sectional nature. However, the rate of recurrent herpes infection history was similarly high. The higher rates of both warts and herpes infections are associated with immunosuppressive treatments.

Rate of bacterial skin infections were not frequent in our study (9.8\%), but acneiform skin lesions were considered among bacterial infections in some studies. The rate of acneiform eruptions was $34.1 \%$ in our study. This rate has been reported between $17-60 \%$ in previous studies $[2,11]$. It is quite natural to find acneiform lesions which are an expected side effect of systemic corticosteroid treatment in renal transplant recipients who depend on low dose systemic corticosteroids nearly lifelong.

Malignant and premalignant skin lesions are more common in renal transplant recipients. Skin cancer rates were reported to be between $4.7-35 \%$ in the published studies $[7,12,15]$. Malignant and premalignant lesions were found in $26 \%$ of patients with a skin cancer rate of $4.8 \%$ in our study. However, $9.8 \%$ of our patients had a history of previously diagnosed skin cancer after transplantation. Renal transplantation patients should be monitored regularly in terms of skin cancers that are found more commonly than society. In addition to these findings, xerotic skin (41.5\%), seborrhoea and sebaceous gland hyperplasia (31.7\%; $24.4 \%$, respectively) and gingival hyperplasia (22\%) were also noted. Rate of xerotic skin was slightly lower in previous studies (2.1-33\%) in comparison to our study $[2,7,10,13]$. This difference can be explained by the fact that our patients are prone to xerosis due to slightly older age compared to previous studies. Moloney et al. [7] reported sebaceous gland hyperplasia in $17.3 \%$ of patients. This rate, which was $24.4 \%$ in our study, was more commonly found in patients who had been taking cyclosporin-A for a long time. Gingival hyperplasia is noted as the most common oral lesion in many studies. However, Kartal et al. [13] and Engin et al. [2] have not observed gingival gland hyperplasia at all. The incidence of gingival hyperplasia was reported between $1.9-44 \%$ in previous studies, compared to $22 \%$ in our study $[11,16,17,18]$. Gingival hyperplasia has also been found more frequently in patients taking cyclosporin-A.

\section{Study Limitations}

The limitation of our study is that it was carried out with relatively few patients due to the circumstances of Coronavirus disease-2019 pandemic. More studies are needed with a greater number of patients who are followed up for a longer period.

\section{Conclusion}

Renal transplant recipients are particularly prone to fungal skin infections such as onychomycosis, viral skin infections such as warts and life-threatening skin cancers. In addition, acneiform eruptions, xerotic skin, sebaceous gland hyperplasia and gingival hyperplasia are also common due to the immunosuppressive medications. Therefore, it is very important to carry out regular dermatological follow-up for renal transplant recipients to prevent possible comorbidities and to enable proper and timely interventions.

\section{Ethics}

Ethics Committee Approval: We conducted our research according to the World Medical Association Declaration of Helsinki and obtained the approval of the Istanbul University Medeniyet Training and Research Hospital Local Ethics Committee (date: 13.01.2021, approval number: 0003).

Informed Consent: Consent form was filled out by all participants.

Peer-review: Internally peer-reviewed.

\section{Authorship Contributions}

Surgical and Medical Practices: M.A.K., H.A., Concept: M.A.K., H.A., Design: M.A.K., S.A.E., N.A., Data Collection or Processing: M.A.K., S.A.E., H.A., Analysis or Interpretation: M.A.K., S.A.E., Literature Search: M.A.K., H.A., Writing: M.A.K., N.A.

Conflict of Interest: No conflict of interest was declared by the authors.

Financial Disclosure: The authors declared that this study received no financial support.

\section{References}

1. Suthanthiran M, Strom TB. Renal transplantation. N Engl J Med 1994;331:365376.

2. Engin B, Alagöz S, Fenjanchi AR, Kutlubay Z, Kote E, Usmanova L. Evaluation of cutaneous manifestations according to the time in renal transplant recipients. Turkderm 2013;47:88-93. 
3. Avermaete A, Altmeyer P, Bacharach-Buhles M. Skin changes and tumours after renal transplantation. Nephron 2002;91:188-194.

4. Capasso A, Bilancio G, Lee MW, Palladino G, Pollastro RM, Simeoni M, Secondulfo C, Ronchi A, Caputo A, Franco R, Zeppa P, Capasso G, Viggiano D. Skin Architecture, Kidney Transplantation, and Their Relationship to Basal and Squamous Cell Carcinomas. Anticancer Res 2020;40:4017-4022.

5. Demirgüneș EF, Ersoy Evans S, Yılmaz R, Şahin S, Yasavul Ü. Cutaneous Manifestations in Renal Transplant Recipients Turkderm-Turk Arch Dermatol Venereol 2008;42:18-21.

6. Ponticelli C, Cucchiari D, Bencini P. Skin cancer in kidney transplant recipients. J Nephrol 2014;27:385-394.

7. Moloney FJ, de Freitas D, Conlon PJ, Murphy GM. Renal transplantation, immunosuppression and the skin: an update. Photodermatol Photoimmunol Photomed 2005;21:1-8.

8. Fiebiger W, Mitterbauer C, Oberbauer R. Health-related quality of life outcomes after kidney transplantation. Health Qual Life Outcomes 2004;2:2.

9. Güleç AT, Demirbilek M, Seçkin D, Can F, Saray Y, Sarifakioglu E, Haberal M. Superficial fungal infections in 102 renal transplant recipients: a case-control study. J Am Acad Dermatol 2003;49:187-192.

10. George L, John GT, Jacob CK, Eapen P, Pulimood S, George R. Skin lesions in renal transplant recipients: a single center analysis. Indian J Dermatol Venereol Leprol 2009;75:255-261.
11. Ghaninejad H, Ehsani AH, Ghiasi M, Noormohammadpour P, Najafi E, Naderi G, Ganji M, Mirnezami M, Nezami R, Kiani P. Benign and malignant skin lesions in renal transplant recipients. Indian J Dermatol 2009;54:247-250.

12. Sandoval M, Ortiz M, Díaz C, Majerson D, Molgó M. Cutaneous manifestations in renal transplant recipients of Santiago, Chile. Transplant Proc 2009;41:3752-3754.

13. Kartal D, Şengün N, Utaş S. Skin Findings in Renal Transplantation Patients. Turk J Dermatol 2013;7:9-12.

14. Dyall-Smith D, Trowell H, Dyall-Smith ML. Benign human papillomavirus infection in renal transplant recipients. Int J Dermatol 1991;30:785-789.

15. Oh CC, Lee HY, Tan BK, Assam PN, Kee TYS, Pang SM. Dermatological conditions seen in renal transplant recipients in a Singapore tertiary hospital. Singapore Med J 2018;59:519-523.

16. Dymock RB. Skin diseases associated with renal transplantation. Australas J Dermatol 1979;20:61-67.

17. Bencini PL, Montagnino G, De Vecchi A, Tarantino A, Crosti C, Caputo R, Ponticelli C. Cutaneous manifestations in renal transplant recipients. Nephron 1983;34:79-83.

18. Chugh KS, Sharma SC, Singh V, Sakhuja V, Jha V, Gupta KL. Spectrum of dermatological lesions in renal allograft recipients in a tropical environment. Dermatology 1994;188:108-112. 